\title{
Avaliação da resistência de espécies de eucalipto à ferrugem (Puccinia psidii Winter)*
}

\author{
Diene Elen Miranda da Silva ${ }^{1}$, Luís Antônio Siqueira de Azevedo ${ }^{2}$, Tathianne Pastana de Souza Poltronieri ${ }^{1}$.
}

\begin{abstract}
${ }^{1}$ Mestre em Fitossanidade e Biotecnologia Aplicada. Instituto de Biologia,Departamento de Fitopatologia e Entomologia - Universidade Federal Rural do Rio de Janeiro, CEP 23890-000, Seropédica/RJ. ${ }^{2}$ Professor Adjunto Doutor do Instituto de Biologia. Departamento de Fitopatologia e Entomologia -Universidade Federal Rural do Rio de Janeiro, CEP 23890-000, Seropédica/RJ. *Parte da dissertação de mestrado do primeiro autor - Mestrado em Fitossanidade e Biotecnologia Aplicada, UFRRJ (2012).
\end{abstract}

Autor para correspondência: Diene Elen Miranda da Silva (dieneelen_ms@hotmail.com).

Data de chegada: 25/02/213. Aceito para publicação em: 06/01/2014.

1870

\section{RESUMO}

Silva, D.E.M.; Azevedo, L.A.S.; Poltronieri, T.P.S. Avaliação da resistência de espécies de eucalipto à ferrugem (Puccinia psidii Winter) Summa Phytopathologica, v.40, n.1, p.54-62, 2014.

A incidência da ferrugem ocorre em mudas no viveiro e em plantas jovens no campo, essa doença causada por Puccinia psidii é uma das mais severas do eucalipto. O presente trabalho teve como objetivo quantificar a resistência parcial das espécies de Eucalyptus propinqua, E. citriodora, E. grandis, E. urophylla, E. microcorys, E. urograndis (E. grandis x E. urophylla), E. robusta, E. saligna, E. dunnie, E. phaeotricha à ferrugem do eucalipto. Para isso foi conduzido experimento em casa de vegetação no Departamento de Entomologia e Fitopatologia da UFRRJ. Foram utilizadas 100 mudas de eucalipto com três meses de idade, obtidas a partir de sementes. O delineamento experimental utilizado foi inteiramente casualizado, com dez tratamentos e dez repetições, sendo uma planta por repetição. A inoculação foi realizada por meio da atomização de folhas com suspensão de uredósporos na concentração de $2 \times 10^{4}$ esporos $/ \mathrm{mL}$, obtidos a partir de pústulas frescas. Em seguida, as mudas foram incubadas em câmara úmida e escura por $48 \mathrm{~h}$. Foram avaliados os parâmetros de resistência: número médio de pústulas por folíolo, severidade, período latente médio e AACPD. Os dados obtidos foram transformados em $\sqrt{x+0,5}$ e $\operatorname{arcsen} \sqrt{x / 100}$, e submetidos à análise de variância e à comparação de médias pelo teste de Scott-Knott ao nível de $5 \%$ de probabilidade, por meio do software SAEG. Foram encontradas diferenças significativas entre as espécies de eucalipto para os parâmetros estudados. Eucalyptus urograndis (E. grandis x E. urophylla) apresentou um menor número médio de pústulas por folíolo, menor severidade, maior período latente médio e valores menores da área abaixo da curva do progresso da doença, tendo dessa forma maior resistência parcial à ferrugem.

Palavras-chave adicionais: Resistência parcial, pústula, severidade, Myrtaceae.

\section{ABSTRACT}

Silva, D.E.M.; Azevedo, L.A.S.; Poltronieri, T.P.S. Evaluation of the resistance of eucalypt species to rust (Puccinia psidii Winter). Summa Phytopathologica, v.40, n.1, p.54-62, 2014.

Rust incidence is frequent among nursery seedlings and young plants in the field; this disease is caused by Puccinia psidii and is one of the most severe affecting Eucalyptus tree. The present study aimed to quantify the partial resistance to eucalypt rust for the species E. propinqua, E. citriodora, E. grandis, E. urophylla, E. microcorys, E. urograndis (E. grandis x E. urophylla), E. robusta, E. saligna, E. dunni and E. phaeotricha. The experiment was conducted in a greenhouse of the Department of Entomology and Plant Pathology of UFRRJ. A total of 100 eucalypt seedlings aged 3 months were obtained from seeds. Experimental design was completely randomized, with 10 treatments and 10 replicates, i.e., 1 plant per replicate. Inoculation was performed by atomizing the leaves with a suspension of urediniospores at the concentration of $2 \times 10^{4}$ spores $/ \mathrm{mL}$, obtained from fresh pustules. Then, seedlings were incubated in a wet,dark chamber for 48 hours. The evaluated parameters of resistance were: mean number of pustules per leaflet, severity, mean latent period and AUDPC. The obtained data were transformed into $\sqrt{x+0,5}$ and $\operatorname{arcsen} \sqrt{x / 100}$, and subjected to analysis of variance and comparison of means according to ScottKnott test at 5\% probability, using the software SAEG. Significant differences were found among eucalypt species for the studied parameters. E. urograndis (E. grandis x E. urophylla) had a smaller mean number of pustules per leaflet, lower severity, greater mean latent period and lower values of area under the disease progress curve, showing thus greater partial resistance to rust.

Additional keywords: partial resistance, pustule, severity, Myrtaceae.

O eucalipto é originário da Austrália, Indonésia e Papua Nova Guiné. O gênero Eucalyptus possui grande destaque no setor florestal, devido sua grande adaptabilidade a diversas condições de solos e climas, além do seu alto potencial como matéria prima para indústria madeireira e a produção de celulose e papel.

Atualmente, o Brasil é o $3^{\circ}$ maior produtor de celulose, a produção brasileira em 2011 chegou a 14 milhões de toneladas.A área de plantio de Eucalyptus no Brasil é de aproximadamente 4,9 milhões hectares, na sua distribuição, o segmento de papel e celulose concentra $71,2 \%$ da área plantada, seguido pelos segmentos de siderurgia e carvão vegetal $(18,4 \%)$, painéis de madeira industrializada $(6,8 \%)$ e produtores independentes $(3,6 \%)$. Os estados de Minas Gerais, São Paulo, Bahia, Mato Grosso do Sul, Rio Grande do Sul, Espírito Santo e Paraná detêm $85,8 \%$ da área de plantio no Brasil. A maior concentração 
de plantios florestais nas regiões Sul e Sudeste do país $(73,8 \%)$ se justifica em função da localização das principais unidades industriais (6).

Até a década de 70, considerava-se que os plantios de eucalipto eram livres de doenças. Entretanto, com o avanço das áreas reflorestadas para regiões mais quentes e úmidas, o plantio de espécies mais produtivas, porém suscetíveis, e a utilização repetitiva de uma mesma área para plantio criaram condições favoráveis à ocorrência de doenças $(18,20)$.

A ferrugem do eucalipto também chamada de ferrugem das mirtáceas, causada por Puccinia psidii Winter é umas das principais doenças da cultura, com potencial para causar perdas em áreas tropicais e subtropicais do mundo que possuam florestas desta espécie $(4,15)$.No Brasil, a ferrugem constitui um sério problema principalmente devido a ocorrência de condições ambientais favoráveis durante todo o ano (5).

A incidência e severidade da doença variam em função da espécie e do genótipo do hospedeiro, região geográfica e época do ano, sendo particularmente exigente quanto às condições de microclima e existência de órgãos juvenis (6).

$\mathrm{O}$ controle de $P$. psidii em eucalipto é baseado principalmente no uso de áreas de escape e de espécies ou progênies resistentes à doença. A ampla variabilidade genética inter e intra-específica para resistência à ferrugem em Eucalyptus spp., permite o controle da doença por meio do plantio de clones, progênies ou espécies resistentes (3).

Segundo Zauza et al. (29), as espécies E. grandis e E. urophylla, possuem ampla variabilidade genética para resistência, apesar de serem consideradas como suscetível e resistente. As demais espécies E. tereticornis, E. pellita e E. camaldulensis são consideradas como resistentes e E. globulus, E. nitens e E. cloeziana como suscetíveis.

A resistência parcial, também chamada de horizontal, quantitativa ou raça não-específica é poligênica e efetiva uniformemente contra uma grande parte ou todas as raças do patógeno (1). Na resistência parcial observa-se uma distribuição contínua de graus de resistência entre as progênies, classificando-as de altamente resistentes até altamente suscetíveis (10).

A resistência parcial afeta principalmente a taxa de velocidade da doença, pois os efeitos na epidemia refletem a atuação da resistência em vários componentes epidemiológicos, como diminuição do tamanho da lesão, do número de esporos produzidos por lesão e do aumento do período latente (10).

A seleção de genótipos para plantios comerciais ou programas de melhoramento tem como principais critérios, as características de crescimento e qualidade da madeira aliadas a resistência a doenças (17).

O presente trabalho foi realizado com o objetivo de avaliar a resistência parcial em dez espécies de eucalipto à ferrugem causada por $P$. psidii em condições de casa de vegetação.

\section{MATERIAL E MÉTODOS}

Para avaliação da resistência parcial de espécies de eucalipto à ferrugem, foi conduzido experimento em Seropédica, na Universidade Federal Rural do Rio de Janeiro, em casa de vegetação, no período de julho a novembro de 2011. Foram semeadas em tubetes com capacidade de substrato de $53 \mathrm{~cm}^{3}$, dez espécies de eucalipto adquiridas no Instituto de Pesquisa e Estudos Florestais (IPEF). As mudas foram transplantadas para sacos plásticos com capacidade para 2,0 $\mathrm{kg}$ de substrato, quando alcançaram uma altura média de quatro centímetros.

Para a preparação do inóculo foram coletadas folhas com pústulas de ferrugem de E. urograndis (E. grandis x E. urophylla) com dois anos de idade. As folhas foram imersas e agitadas por cinco minutos em erlemeyers com $500 \mathrm{~mL}$ de água destilada esterilizada (ADE) e três gotas de Tween $80 \%$. A determinação e calibração da concentração de inóculo foram estimadas com o auxílio do hemocitômetro. A suspensão de uredósporos foi calibrada para a concentração de $2 \times 10^{4}$ esporos $/ \mathrm{mL}$.

O delineamento experimental utilizado foi o inteiramente casualizado, com dez tratamentos e dez repetições, sendo uma planta por repetição, totalizando 100 mudas. Foram avaliados os seguintes parâmetros de resistência parcial: número
Tabela 1. Espécies de eucalipto avaliadas quanto a resistência à Puccinia psidii em Seropédica - RJ.

\begin{tabular}{c|c|c}
\hline $\begin{array}{c}\text { Espécies de } \\
\text { eucalipto } \\
\text { E. citriodora }\end{array}$ & $\begin{array}{c}\text { Grau de } \\
\text { Melhoramento* }\end{array}$ & Procedência \\
E. saligna & APS F1 & Anhembi-SP \\
E. grandis & APS F1 & Itatinga - SP \\
E. urophylla & APS F1 & Anhembi-SP \\
E. grandis x E. urophylla & APS F1 & Anhembi-SP \\
E. dunni & PSM F3 & Anhembi-SP \\
E. robusta & APS F2 & Itatinga -SP \\
E. propinqua & APS F2 & Itatinga -SP \\
E. microcorys & APS F1 & Anhembi-SP \\
E. phaeotricha & APS F1 & Anhembi-SP \\
\hline
\end{tabular}

* Graus de Melhoramento

APS - Área de Produção de Sementes

PSM - Pomar de sementes por mudas

Fn ( $n=1$ a 5) - Geração de Melhoramento

Fonte: IPEF, 2012.

médio de pústulas por folíolo, severidade da ferrugem, período latente médio (PLM) e área abaixo da curva do progresso da doença (AACPD).

Para a quantificação das variáveis monocíclicas, plantas das dez espécies de eucalipto com três meses de idade foram inoculadas com o fungo. A inoculação foi realizada por meio da atomização de folhas com suspensão de uredosporos na concentração de $2 \times 10^{4}$ esporos $/ \mathrm{mL}$, obtidos a partir de pústulas de ferrugem (7). A atomização das folhas foi realizada ao final da tarde em casa de vegetação, com um pulverizador manual de capacidade para um litro. Em seguida, as mudas foram incubadas em câmara úmida e escura por 48 horas. As variáveis temperatura e umidade relativa da casa de vegetação não puderam ser registradas devido à ausência de equipamento adequado para isso.

As avaliações consistiram na contagem do número de pústulas por folíolo e a quantificação da severidade em quatro folhas marcadas. A primeira avaliação foi realizada aos dez dias após a inoculação e as demais no espaço de quatro em quatro dias, totalizando cinco avaliações. Para avaliação da severidade da doença utilizou-se a escala diagramática de quantificação da resistência à ferrugem do eucalipto, elaborada por Junghans et al. (21). A partir do número de pústulas encontradas foi calculado o Índice de infecção de Mckinney (24) com emprego da equação:

$$
\mathrm{INF}=\frac{\sum(\text { grau da escala } \mathrm{x} \text { frequência }) \times 100}{\left(\mathrm{n}^{\mathrm{o}} \text { total de unidades } \mathrm{x} \text { grau máximo da escala }\right)}
$$

Para calcular o período latente médio (PLM), foi empregada a equação de Shaner e Hess (28):

$\mathrm{PLM}=\sum$ Pi Ti em que:

$\mathrm{Pi}=$ proporção de pústulas novas surgidas na i-ésima observação, em relação ao número final de pústulas na n-ésima observação;

$\mathrm{Ti}$ = número de dias decorridos desde a inoculação até a i-ésima observação, $\mathrm{e}$

$\mathrm{n}=$ número total de observações.

Com base também nessas variáveis, calculou-se a área abaixo da curva do progresso da doença (11), tomando-se como referência os dados de severidade e número médio de pústulas por folíolo.

$\mathrm{AACPD}=\sum\left[\left(\mathrm{Yi}+\mathrm{Y}_{\mathrm{i}+1}\right) / 2\right] \times\left[\mathrm{X}_{\mathrm{i}+1}-\mathrm{Xi}\right]$ em que:

$\mathrm{Yi}=$ média da doença (por unidade de tempo) na i-ésima observação;

$\mathrm{Xi}=$ tempo em dias na i-ésima observação, e

$\mathrm{n}=$ número total de observações.

Os dados dos parâmetros número médio de pústulas por folíolo, PLM e AACPD foram transformados em $\sqrt{x+0,5}$ e os da variável de severidade em 


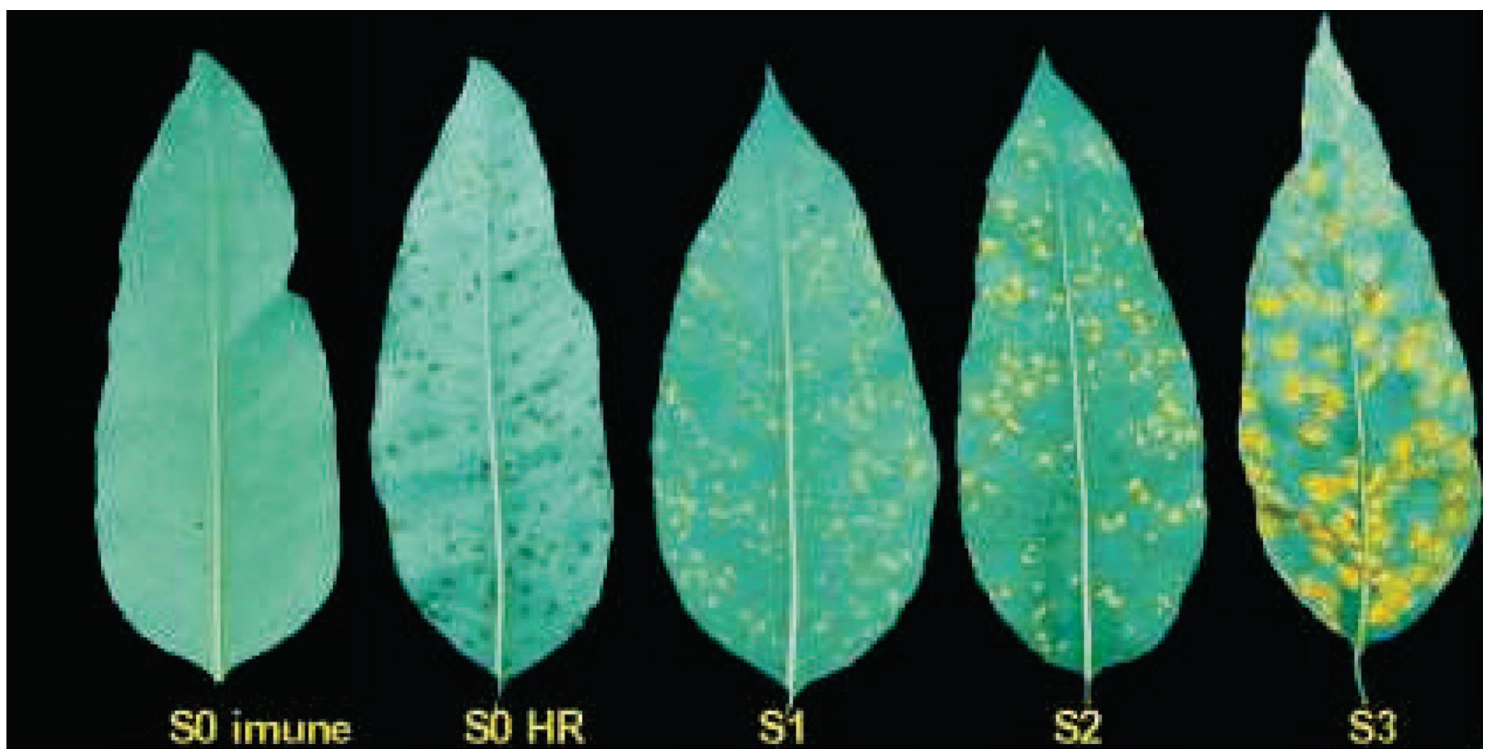

Figura 1. Escala de notas para avaliação da resistência à ferrugem do eucalipto (Eucalyptus sp.), com quatro classes de severidade: $\mathrm{S} 0=$ imunidade ou reação de hipersensibilidade do tipo "fleck" ou necrótico; $\mathrm{S} 1$ = pústulas < 0,8 $\mathrm{mm}$ de diâmetro; $\mathrm{S} 2$ = pústulas de 0,8 a 1,6 mm de diâmetro; e $\mathrm{S} 3=$ pústulas $>1,6 \mathrm{~mm}$ de diâmetro. Plantas nas classes de severidade S0 e S1 são consideradas resistentes, enquanto S2 e S3, suscetíveis.

Fonte: Junghans et al., 2003.

$\operatorname{arcsen} \sqrt{x / 100}$, e submetidos à análise de variância e à comparação de médias pelo teste de Scott-Knott ao nível de 5\% de probabilidade, por meio do software SAEG. Realizou-se ainda a correlação residual entre os parâmetros avaliados, por meio do software GENES.

\section{RESULTADOS E DISCUSSÃO}

Número médio de pústulas por folíolo

A média do número de pústulas por folíolo variou de 1,21 a 12,77. Houve diferenças significativas entre as médias das espécies, pelo teste de Scott Knot ao nível de $5 \%$. Neste ensaio quatro espécies apresentaram um menor número de pústulas por folíolo: E. grandis x E. urophylla, E. propinqua, E. dunni e E. robusta, o que permite afirmar que essas espécies comportaram-se como mais resistentes à ferrugem do eucalipto (P. psidii).

No progresso da doença a partir do parâmetro do número médio de pústulas por folíolo observa-se que a doença manteve-se praticamente estável no decorrer das cinco avaliações nas espécies E. robusta, E. dunni, E. pronpinqua e E. grandis x E. urophylla, demonstrando que essas espécies comportaram-se como mais resistentes já que ocorreu uma redução da taxa de epidemia através da diminuição do número de pústulas.

\section{Severidade}

A média da severidade da ferrugem nas espécies de eucalipto em casa de vegetação variou de 12,81 a 35,64\% de área foliar infectada (Tabela 2). Houve diferença significativa entre as médias. A partir dos resultados obtidos, é possível afirmar que as espécies E. saligna, E. robusta e E. microcorys podem ser consideradas como mais resistentes à ferrugem. A espécie $E$. urograndis ( $E$. grandis x E. urophylla) apresentou uma severidade média de 18,80\% porém diferenciou-se estatisticamente do grupo das mais resistentes.

Observa-se na evolução da doença, no que se refere à severidade, que as espécies E. dunni, E. phaeotricha e E. citriodora foram as que apresentaram maior severidade da doença, comportando-se como suscetíveis. Enquanto, que na espécie $E$. robusta a enfermidade manteve-se estável durante as avaliações, podendo ser considerada como mais resistente à ferrugem. As espécies $E$. grandis $\mathrm{x}$ E. urophylla $\mathrm{e}$ E. saligna exibiram baixa evolução da ferrugem durante

Tabela 2. Número médio de pústulas por folíolo, severidade e período latente médio de Puccinia psidii, em dez espécies de eucalipto, em condições de casa de vegetação.

\begin{tabular}{|c|c|c|c|}
\hline Espécie & Número médio de pústulas ${ }^{(1)}$ & Severidade $(\%)^{(1)}$ & Período latente médio ${ }^{(1)}$ \\
\hline E. citriodora & $12,77 \mathrm{a}$ & $32,13 \mathrm{a}$ & $16,03 \mathrm{a}$ \\
\hline E. saligna & $9,93 \mathrm{~b}$ & $17,98 \mathrm{c}$ & $8,47 \mathrm{a}$ \\
\hline E. phaeotricha & $8,52 \mathrm{~b}$ & 34,47 a & $9,82 \mathrm{a}$ \\
\hline E. grandis & $8,01 \mathrm{~b}$ & $30,64 \mathrm{a}$ & $14,23 \mathrm{a}$ \\
\hline E. urophylla & $3,77 \mathrm{c}$ & $19,98 \mathrm{~b}$ & $8,42 \mathrm{a}$ \\
\hline E. microcorys & $3,38 \mathrm{c}$ & $12,81 \mathrm{c}$ & $10,21 \mathrm{a}$ \\
\hline E. grandis $x$ E. urophylla & $3,20 \mathrm{~d}$ & $18,80 \mathrm{~b}$ & 13,96 a \\
\hline E. propinqua & $1,78 \mathrm{~d}$ & $22,47 \mathrm{~b}$ & $12,75 \mathrm{a}$ \\
\hline E. dunni & $1,54 \mathrm{~d}$ & 35,64 a & $15,04 \mathrm{a}$ \\
\hline E. robusta & $1,21 \mathrm{~d}$ & $14,80 \mathrm{c}$ & $9,02 \mathrm{a}$ \\
\hline CV (\%) & 56,18 & 55,12 & 58,36 \\
\hline
\end{tabular}

${ }^{(1)}$ Dados originais sem transformação. Número médio de pústulas. Médias seguidas da mesma letra não diferem entre si, ao nível de 5\%, pelo teste de Scott Knott. Cada repetição refere-se a média de dez plantas. 


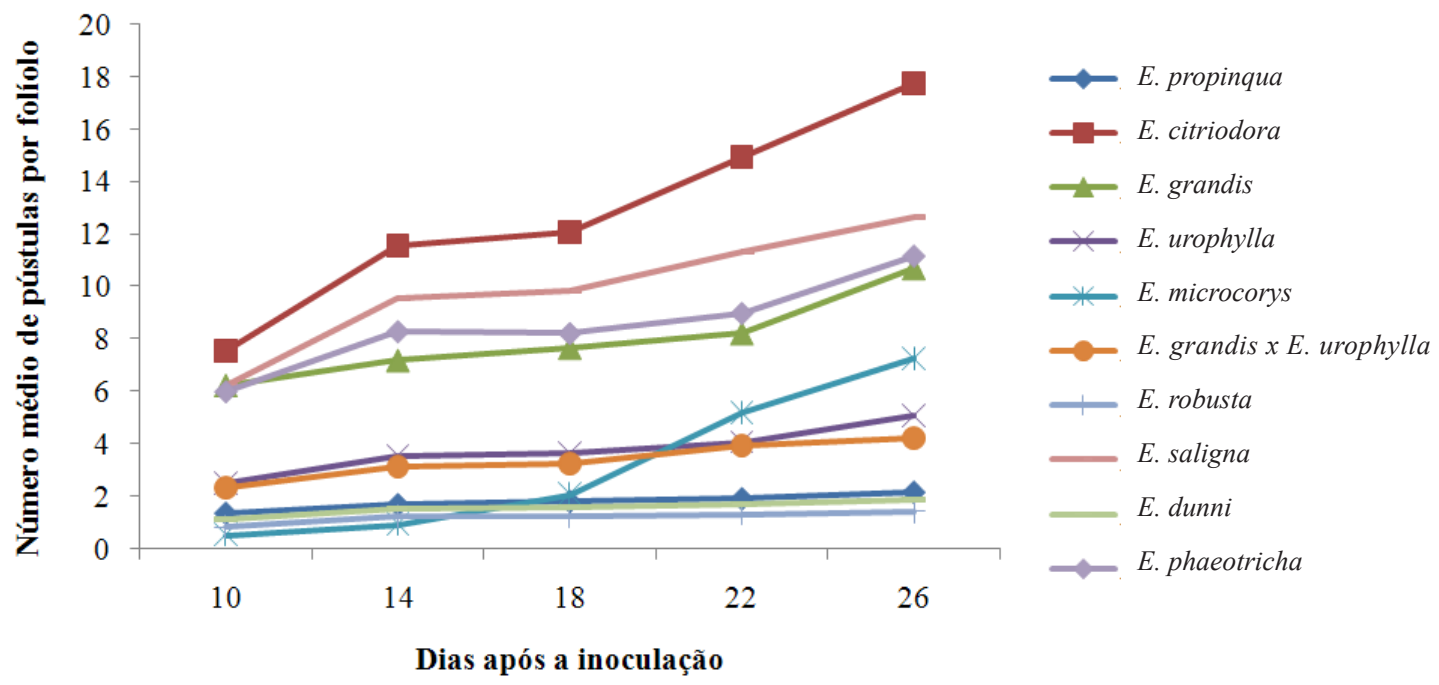

Figura 2.Número médio de pústulas de Puccinia psidii, por folíolo, em dez espécies de eucalipto, em condição de casa de vegetação.

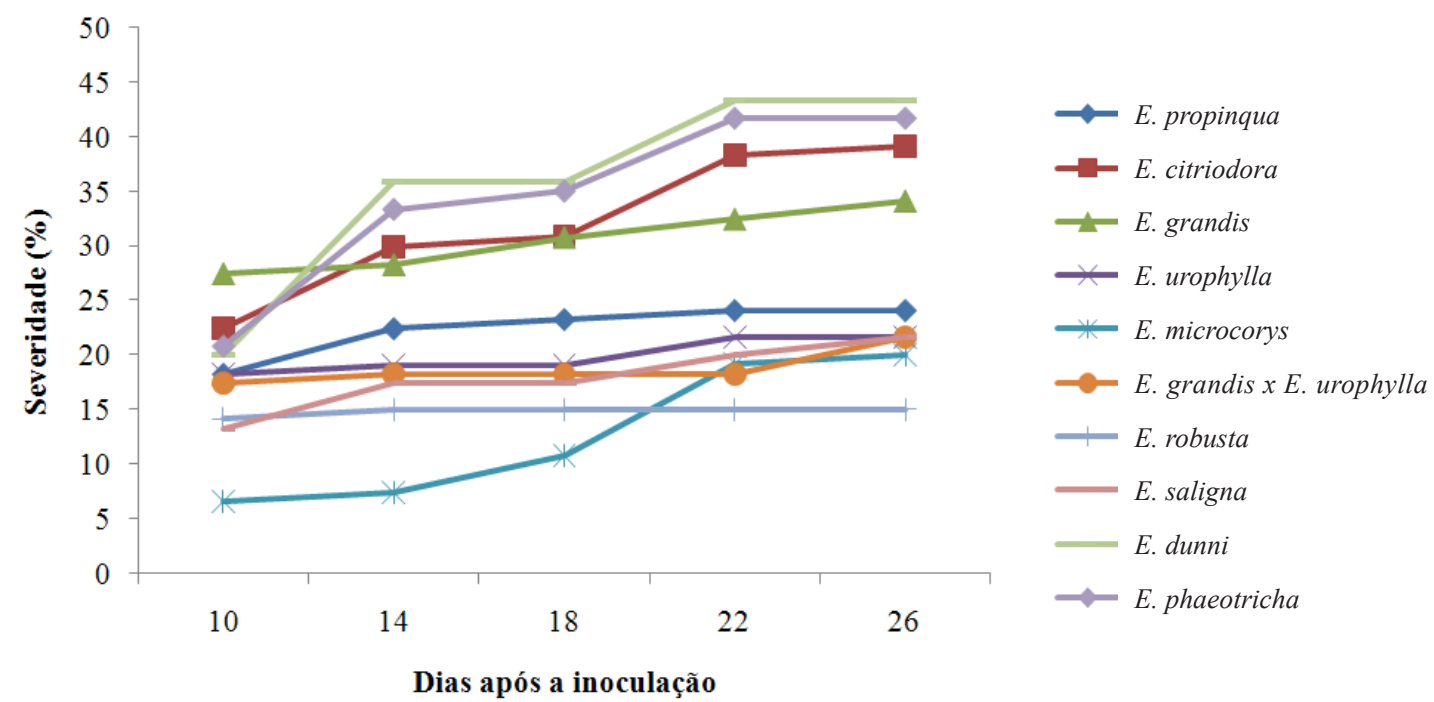

Figura 3. Severidade (\% da área foliar infectada) da ferrugem em dez espécies de eucalipto, em condições de casa de vegetação.

as avaliações, classificando-as como mediamente resistentes.

As diferenças nos resultados de espécies resistentes entre os parâmetros de número médio de pústulas por folíolo e severidade podem ser explicadas pela escala de notas utilizada na avaliação do parâmetro em questão, que leva em consideração a classe de severidade de acordo com o tamanho da pústula. Segundo Junghans et al. (21), não existe relação direta entre o tamanho de pústulas e sua distribuição na folha, neste caso, a resistência reflete a capacidade do hospedeiro de restringir o crescimento e desenvolvimento do patógeno no órgão inoculado, enquanto o número e a distribuição de pústulas, relaciona-se também com a distribuição de esporos do patógeno durante a inoculação.

Os resultados deste ensaio corroboram com Santos (27), que em estudo sobre a resistência genética à ferrugem através do parâmetro de severidade avaliada pela escala de notas para avaliação da resistência à ferrugem do eucalipto de Junghans, verificou que E. urophylla apresentou maior número de plantas resistentes que $E$. grandis.

\section{Período latente médio (PLM)}

A média do período latente médio das espécies variou entre 8,42 a 16,03 dias neste ensaio (Tabela 2). Não houve diferença estatisticamente significativa entre as médias pelo teste de Scott Knott ao nível de 5\% de probabilidade.

Porém se considerarmos que o período latente de $P$. psidii é relativamente curto, variando em média de cinco a sete dias $(2,26)$, espécies com período latente médio superior a doze dias, poderiam ser classificadas como possuidoras de resistência parcial, como as espécies E. propinqua, E. grandis x E. urophylla, E. grandis, E. dunni e E. citriodora.

A variação das médias de período latente médio entre as espécies observada neste trabalho também tem sido verificada por diversos autores, com outras espécies e procedências de Eucalyptus spp. (12, 13, 25).

AZEVEDO et al. (8) e MARTINS et al. (23), avaliando a resistência em casa de vegetação de genótipos de soja à $P$. pachyrhizi também utilizaram o período latente médio como parâmetro de resistência, já que a ferrugem lenta é considerada como uma forma de resistência parcial.

Área abaixo da curva do progresso da doença (AACPD)

A média dos valores da área abaixo da curva do progresso da doença (AACPD) para número médio de pústulas por folíolo variou de 21,20 a 
207,85 e para a área abaixo da curva do progresso da doença (AACPD) para severidade variou de 237,86 a 519,40 . Houve diferença significativa entre as médias. As espécies E. citriodora, E. dunni, E. phaeotricha e E. grandis apresentaram valores significativamente mais elevados de AACPD, logo foram mais suscetíveis à ferrugem. Por outro lado, as espécies E. urophylla, $E$. grandis x E. urophylla, E. microcorys, E. propinqua, E. saligna e E. robusta comportaram-se como mais resistentes à ferrugem do eucalipto, devido aos

Tabela 3. Área abaixo da curva do progresso da doença de Puccinia psidii, dos parâmetros de número médio de pústulas e severidade, em dez espécies de eucalipto em condições de casa de vegetação.

\begin{tabular}{ccc}
\hline Espécie & AACPD Pust $^{(1)}$ & AACPD Sev $^{(1)}$ \\
\hline E. citriodora & $207,85 \mathrm{a}$ & $519,40 \mathrm{a}$ \\
E. dunni & $160,70 \mathrm{a}$ & $586,14 \mathrm{a}$ \\
E. phaeotricha & $138,85 \mathrm{a}$ & $564,42 \mathrm{a}$ \\
E. grandis & $126,30 \mathrm{a}$ & $489,50 \mathrm{a}$ \\
E. urophylla & $60,25 \mathrm{~b}$ & $319,58 \mathrm{~b}$ \\
E. urograndis & $54,45 \mathrm{~b}$ & $297,66 \mathrm{~b}$ \\
E. microcorys & $48,50 \mathrm{~b}$ & $199,66 \mathrm{~b}$ \\
E. propinqua & $28,50 \mathrm{~b}$ & $364,42 \mathrm{~b}$ \\
E. saligna & $24,80 \mathrm{~b}$ & $289,68 \mathrm{~b}$ \\
E. robusta & $21,20 \mathrm{~b}$ & $237,86 \mathrm{~b}$ \\
\hline CV $(\%)$ & 67,41 & 55,50 \\
\hline
\end{tabular}

${ }^{(1)}$ Dados originais sem transformação. Número médio de pústulas. Médias seguidas da mesma letra não diferem entre si, ao nível de $5 \%$, pelo teste de Scott Knott. Cada repetição refere-se a média de 10 plantas. mais baixos valores de AACPD.

A área abaixo da curva do progresso da doença também tem sido utilizada por diversos autores para quantificar níveis de resistência parcial com outros patossistemas $(8,9,14,16,22,23)$. Porém não há estudos epidemiológicos sobre o patossistema $P$. psidii x eucalipto que utilizem esse parâmetro policíclico na avaliação da resistência quantitativa ou parcial.

\section{Correlação residual entre os parâmetros de resistência parcial}

Houve correlação residual significativa entre todos os parâmetros com o r crítico de 0,267 a $1 \%$. As mais altas correlações entre os parâmetros de resistência parcial foram observadas entre o número médio de pústulas por folíolo e a severidade $(r=0,73)$, bem como entre área abaixo da curva do progresso da doença baseada na variável de número médio de pústulas (AACPD Pus) e a severidade $(\mathrm{r}=0,73)$, e entre área abaixo da curva do progresso da doença baseada na variável de severidade (AACPD Sev) e o número médio de pústulas ( $\mathrm{r}$ $=0,73)$. Dessa forma, concluem-se que as variáveis severidade e número médio de pústulas por folíolo devem ser avaliadas nos estudos epidemiológicos de $P$. psidii versus eucalipto. As correlações entre a área abaixo da curva do progresso da doença baseada no parâmetro de número médio de pústulas (AACPD Pus) e número médio de pústulas $(\mathrm{r}=0,99)$ e área abaixo da curva do progresso da doença baseada no parâmetro de severidade (AACPD Sev) e severidade $(\mathrm{r}=0,99)$, não foram consideradas como as mais altas correlações por serem dependentes matemáticas.

Curva de progresso da ferrugem nas espécies de eucalipto

Através dos gráficos com a curva de progresso da ferrugem, nas dez espécies avaliadas, observa-se um crescimento linear da doença com o coeficiente de determinação $\left(\mathrm{R}^{2}\right)$ variando de 80,67 a $96,38 \%$ no parâmetro de número médio

Tabela 4. Correlação residual entre os parâmetros de resistência parcial à Puccinia psidii em casa de vegetação.

\begin{tabular}{cccccc}
\hline Parâmetros & PLM & PUS & SEV & AACPD Pus & AACPD Sev \\
\hline PLM $^{(1)}$ & 1 & 0,33 & 0,62 & 0,31 & 0,61 \\
PUS $^{(2)}$ & & 1 & 0,73 & 0,99 & 0,73 \\
SEV $^{(3)}$ & & & 1 & 0,73 & 0,99 \\
AACPD Pus $^{(4)}$ & & & & 1 & 0,72 \\
AACPD Sev $^{(5)}$ & & & & & 1 \\
\hline
\end{tabular}

(1) PLM - Período latente médio

${ }^{(2)}$ PUS - Número médio de pústulas por folíolo

${ }^{(3)} \mathrm{SEV}$ - Severidade

${ }^{(4)}$ AACPD Pus - Área abaixo da curva do progresso da doença baseada no parâmetro de número médio de pústulas

(5) AACPD Sev - Área abaixo da curva do progresso da doença baseada no parâmetro de severidade

* Correlação significativa entre todos os parâmetros a $1 \%$.
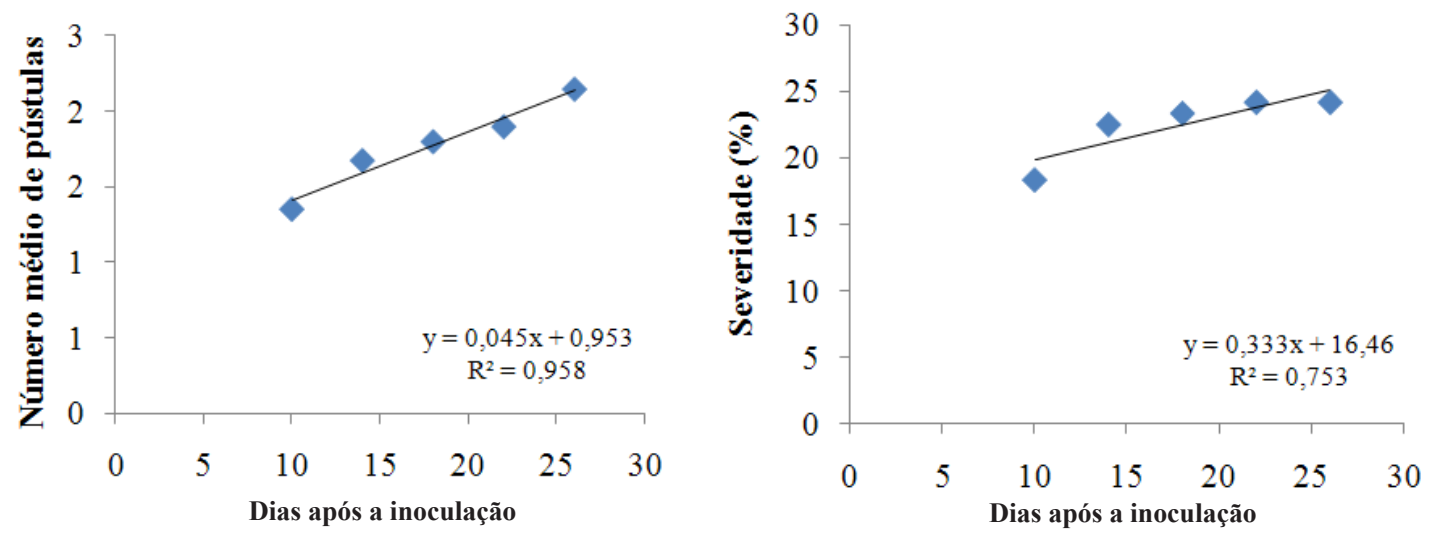

Figura 4. Regressão da curva do progresso da ferrugem em Eucalyptus propinqua. 

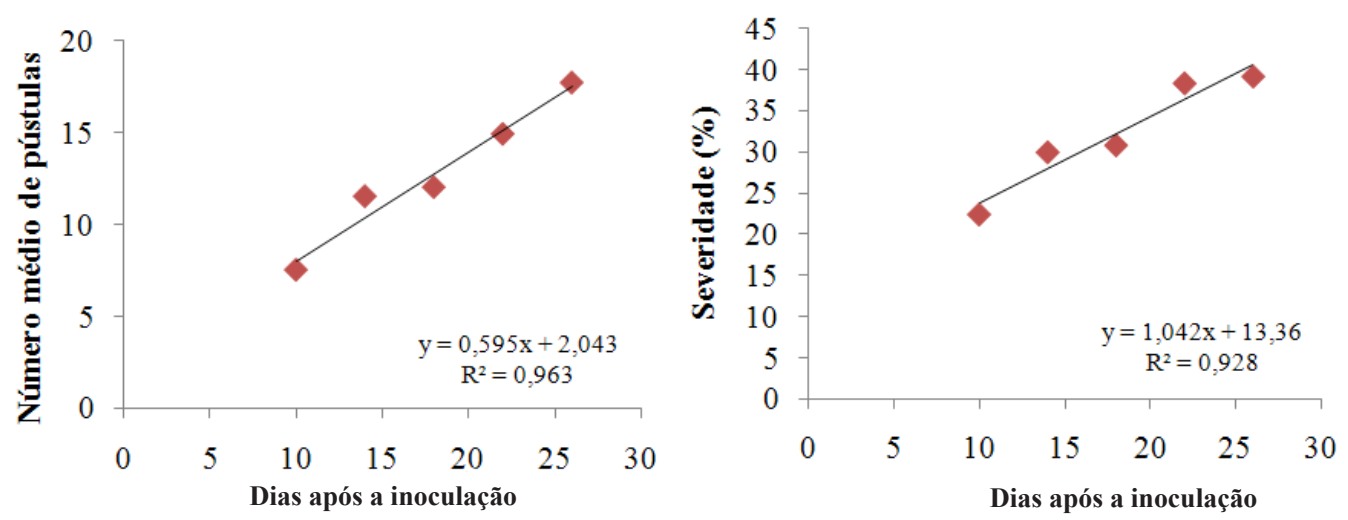

Figura 5. Regressão da curva do progresso da ferrugem em Eucalyptus citriodora.
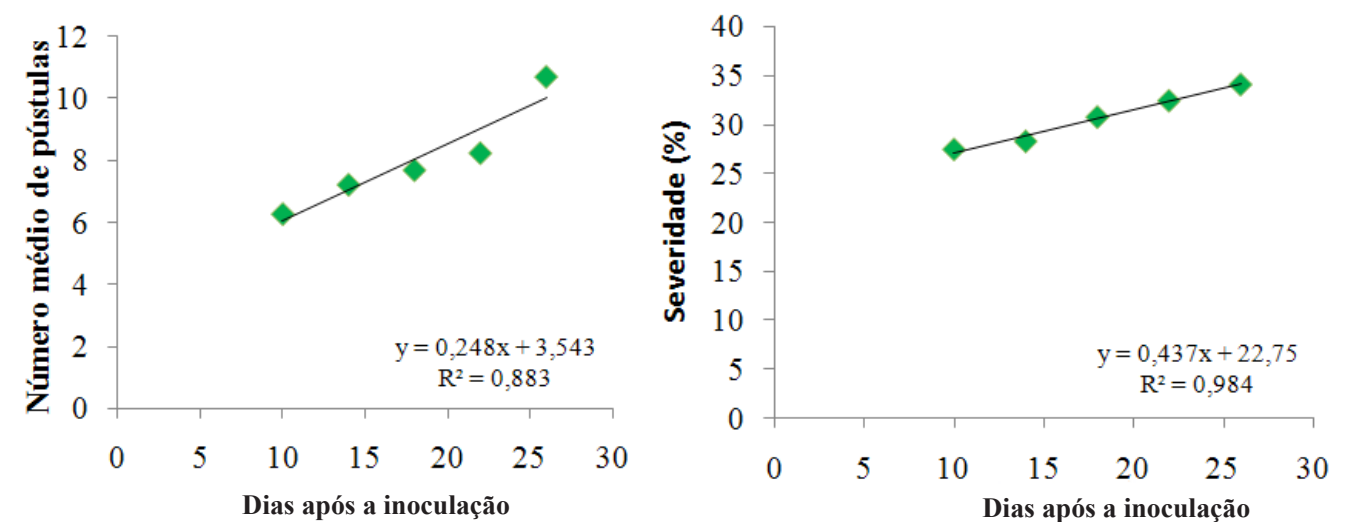

Figura 6. Regressão da curva do progresso da ferrugem em Eucalyptus grandis.
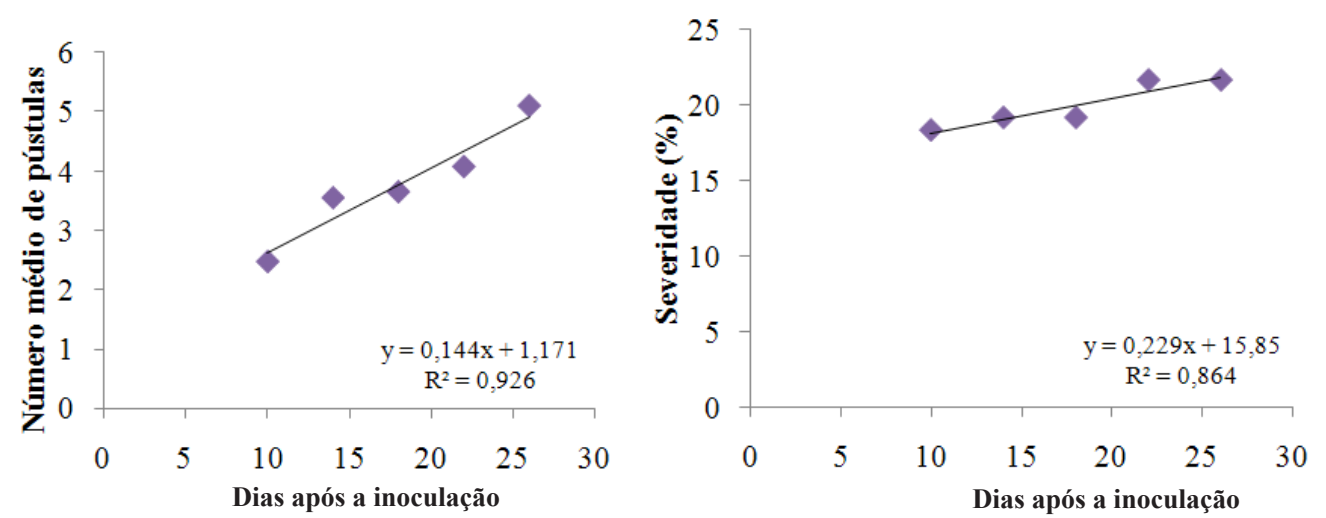

Figura 7. Regressão da curva do progresso da ferrugem em Eucalyptus urophylla.
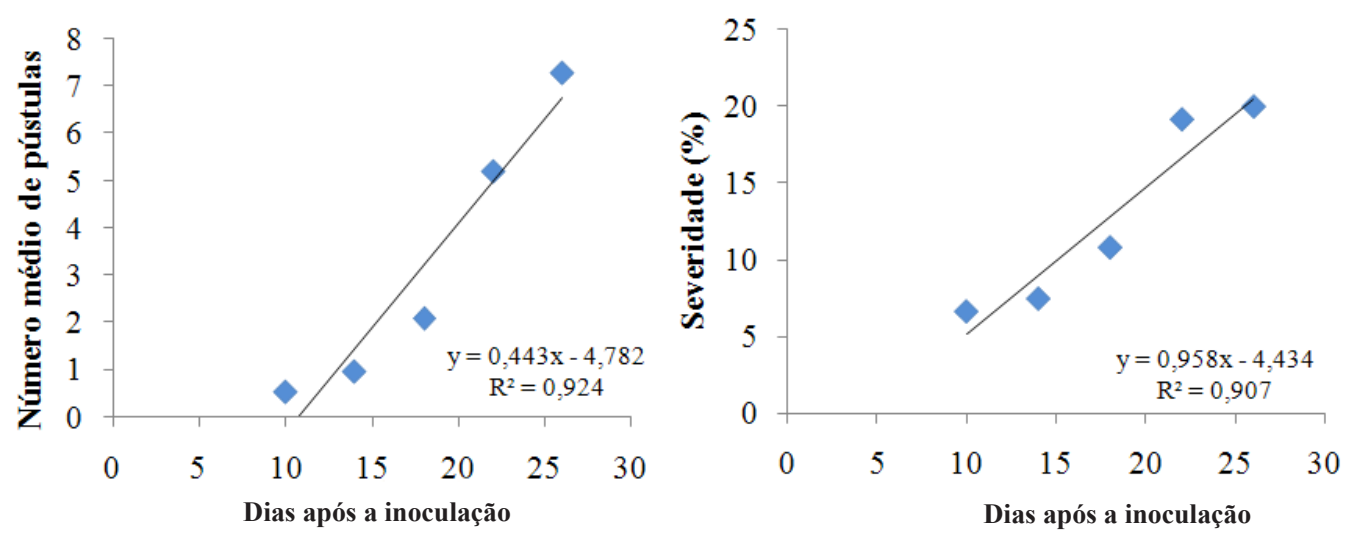

Figura 8. Regressão da curva do progresso da ferrugem em Eucalyptus microcorys. 

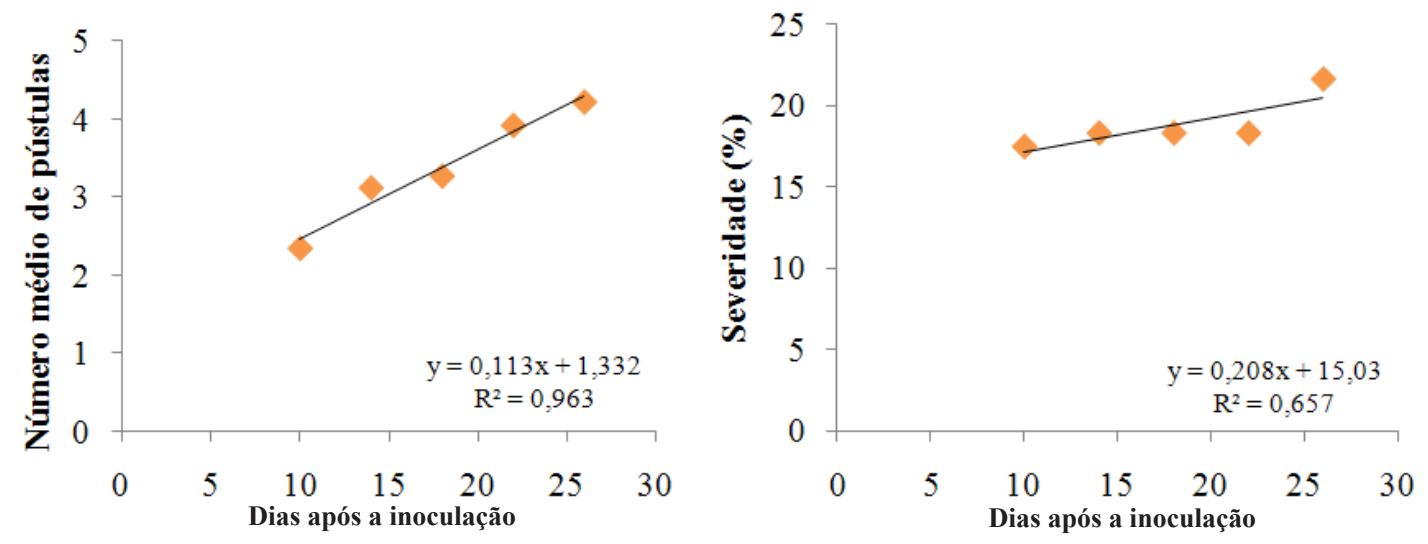

Figura 9. Regressão da curva do progresso da ferrugem em Eucalyptus grandis x E. urophylla.
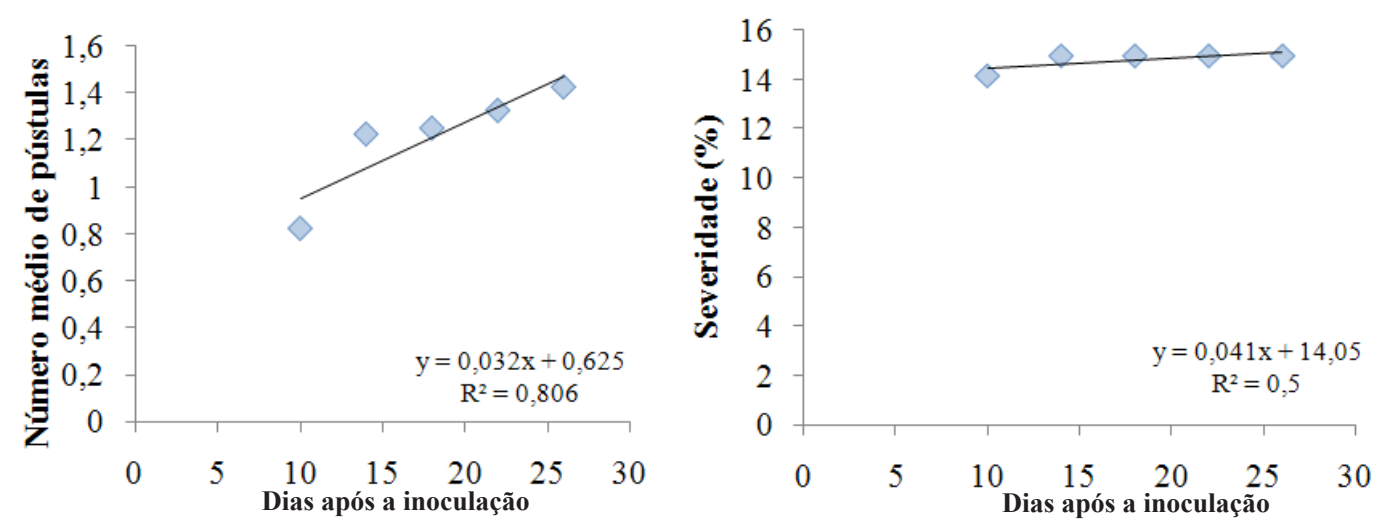

Figura 10. Regressão da curva do progresso da ferrugem em Eucalyptus robusta.
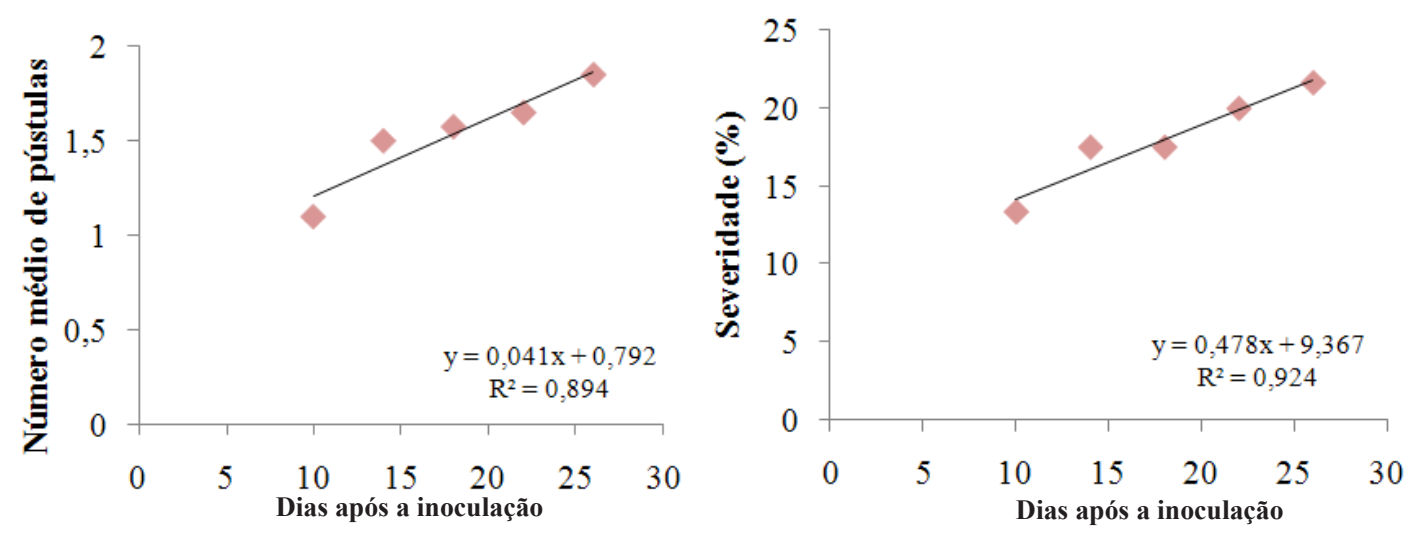

Figura 11. Regressão da curva do progresso da ferrugem em Eucalyptus saligna.
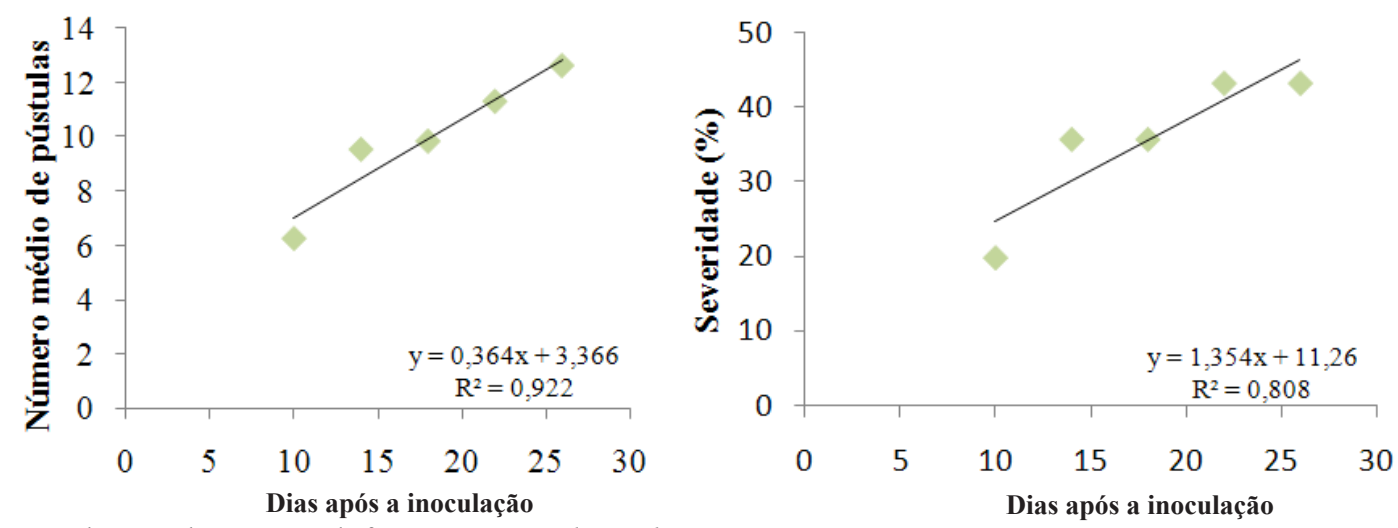

Figura 12. Regressão da curva do progresso da ferrugem em Eucalyptus dunni. 

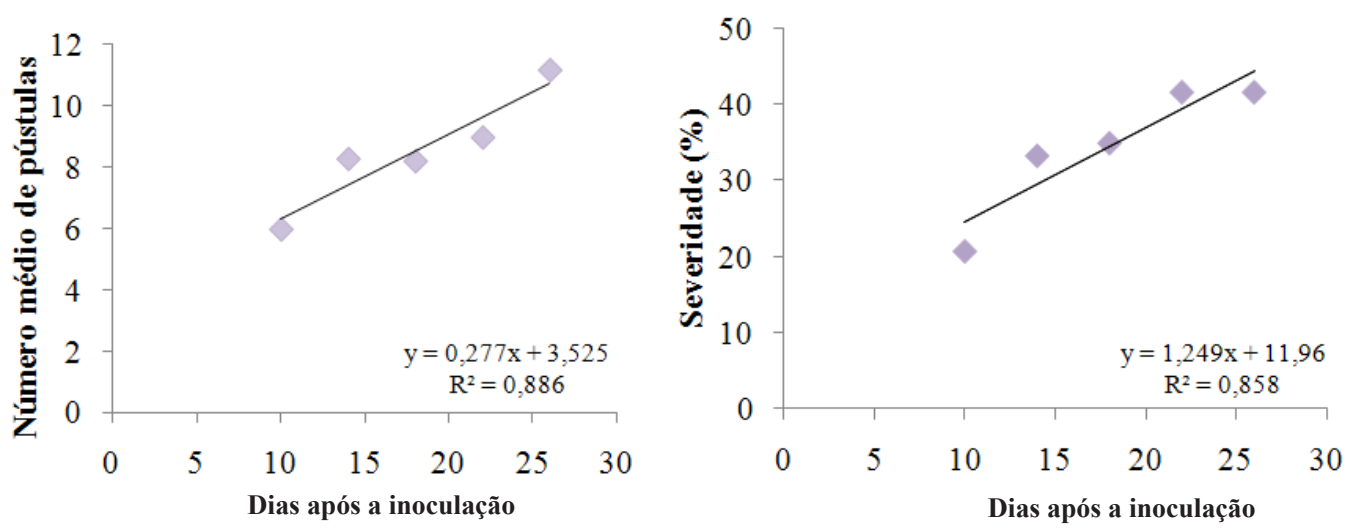

Figura 13. Regressão da curva do progresso da ferrugem em Eucalyptus phaeotricha.

de pústulas por folíolo e $\mathrm{R}^{2}$ de 50,00 a 98,43\% no parâmetro de severidade.

As espécies E. propinqua, E. urograndis (E. grandis x E. urophylla), E. robusta e E. saligna apresentaram uma menor taxa de infecção da doença comportando-se como mais resistentes à ferrugem quando avaliado o número médio de pústulas por folíolo. Enquanto que as espécies E. citriodora, E. dunni e E. phaeotricha exibiram um maior número de pústulas por folíolo, com o desenvolvimento da ferrugem mais acentuado, o que as caracteriza como suscetíveis.

No parâmetro severidade verifica-se que o E. robusta, E. saligna, E. urograndis (E. grandis x E. urophylla) e E. urophylla apresentaram menor desenvolvimento micelial intercelular, resultando em pústulas com menores diâmetros, classificando-as como espécies mais resistentes à ferrugem. As espécies E. citriodora, E. dunni e E. phaeotricha exibiram pústulas maiores comportando-se como mais suscetíveis.

A maior suscetibilidade da espécie E. phaeotricha à ferrugem possivelmente está relacionada com a taxa de crescimento mais lenta nessa espécie em relação às demais.

\section{CONCLUSÕES}

De acordo com os dados obtidos neste trabalho, conclui-se que a espécie Eucalyptus urograndis (E. grandis x E. urophylla) apresentou resistência parcial à Puccinia psidii exibindo uma somatória de efeitos sobre as variáveis analisadas, apresentando menor número médio de pústulas por folíolo, menor severidade, maior período latente médio e valores menores da área abaixo da curva do progresso da doença.

As espécies E. saligna e E. urophylla foram moderadamente resistentes apenas quando se avaliou número médio de pústulas por folíolo, severidade e AACPD e E. robusta quando se quantificou número médio de pústulas por folíolo e severidade.

\section{REFERÊNCIAS BIBLIOGRÁFICAS}

1. Agrios, G. N. Plant Pathology. 5 ed. Amsterdam: Elsevier Academic Press, 2005. $922 \mathrm{p}$

2. Alfenas, A. C.;Brommonschenkel, S. H.;Maffia, L. A.;Junghans, D. T.; Xavier, A. A.; Ruiz, R. A. R.;Oda, S.; Mello, E. J. Ferrugem do eucalipto: etiologia, epidemiologia e controle. In: Seminário de ferrugem do eucalipto,1, 2000. Botucatu.Anais. Piracicaba: Editora IPEF, 2000, 6 p.

3. Alfenas, A. C.; Zauza, E. A. V.; Mafia, R. G.; Assis, T. F. de. Clonagem e doenças do eucalipto. Viçosa: Editora UFV, 2004. 442p.

4. Alfenas, A. C.; Zauza, E. A. V.; Mafia, R. G.; Assis, T. F. de. Clonagem e doenças do eucalipto. 2 ed. Viçosa: Editora UFV, 2009. 500p.

5. Aparecido, C.C.; Figueiredo, M.B.; Furtado, E.L. Influência da temperatura sobre a infecção, formação de teliosporos e produção de basidiósporos por Pucciniapsidii. Summa Phytopathologica,Botucatu, v.29, p.239-243, 2003.
6. Associação Brasileira Florestal dos Produtores de Florestas Plantadas. Anuário Estatístico da ABRAF 2012, ano base 2011. 2012. Disponível em: <http://www.abraflor.org.br/estatisticas/ABRAF12/ABRAF12-BR. pdf>. Acesso em: 05 de julho de 2012.

7. Azevedo, L. A. S. Resistência parcial de genótipos de soja a Phakopsora pachyrhizi e sua interação com fungicidas. 2005. 68 f. Tese (Doutorado em Agronomia - Produção Vegetal) - Universidade Estadual Paulista, Jaboticabal.

8. Azevedo, L. A. S.; Juliatti, F. C.; Barreto, M. Resistência de genótipos de soja a Phakopsorapachyrhizi. Summa Phytopathologica, Botucatu, v. 33, n. 3. 2007.

9. Balardin, R. S.; Navarini, L.; Dallagnol, L. J. Epidemiologia da Ferrugem da Soja. In: Juliatti, C. F.; Polizel, C. A.; Hamawaki, T. O. In: Workshop Brasileiro sobre a Ferrugem Asiática; 2005, Uberlândia. Coletânea: EDUFU, p.39-50, 2005.

10. Camargo, L. E. A. Controle Genético. In: Amorin, L.; Rezende, J. A. M.; Bergamim Filho, A. Manual de fitopatologia: princípios e conceitos. 4 ed. São Paulo: Agronômica Ceres, 2011.v. 1, p. 325 - 340.

11. Campbell, C. L.; Madden, L. V. Introduction to plant disease epidemiology. New York, John Willey, 1990. 532p.

12. Castro, H. A. Padronização de metodologia de inoculação e avaliação de resistência de Eucalyptus sp. à ferrugem causada por Puccinia psidii Winter. 1983. 116p. Tese (Doutorado em Fitopatologia) - Escola Superior de Agricultura Luiz de Queiroz, Universidade de São Paulo, Piracicaba.

13. Castro, H. A., Krugner, T. L.; Bergamin Filho, A. Especialização fisiológica no sistema Eucalyptusgrandis - PucciniapsidiiWinter. Ciência e Prática Lavras, Lavras, v. 9, p. 80-92, 1985.

14. Chaves, M. S.; Martinelli, J.A.;Federizzi, L.C. Resistência quantitativa à ferrugem da folha em genótipos de aveia branca:I - Caracterização da reação em condições de campo. Fitopatologia Brasileira, v. 29, p. 39-46, 2004.

15. Coutinho, T.A.; Wingfield, M.J.; Alfenas, A.C.; Crous, P.W. Eucalyptus rust: a disease with the potential for serious international implications. Plant Disease,St. Paul,v.82, p. 819-925, 1998.

16. Cruvinel, A. R.; Ottoni, G.; Lima, L. P.; Godoy, C. V. Utilização da área abaixo da curva de progresso da doença relativa para estudos epidemiológicos da ferrugem asiática da soja. In: Reunião de Pesquisa de Soja da Região Central do Brasil,26a , 2004, Ribeirão Preto. Anais.Londrina: Embrapa Soja, 2004. p. 186.

17. Fonseca, S. M.; Resende, M. D. V.; Alfenas, A. C.; Guimaraes, L. M. S.; Assis, T. F.; Grattapaglia, D. Manual prático de melhoramento genético do eucalipto. Viçosa:Editora UFV, 2010. 200p.

18. Furtado, E. L.; Santos, C.A. G.; Masson, M. V. Impacto potencial das mudanças climáticas sobre a ferrugem do eucalipto no Estado de São Paulo. In: Ghini, R.; Hamada, E. Mudanças climáticas: impactos sobre doenças de plantas no Brasil.Brasília, DF: Embrapa Informação Tecnológica, 2008. p. 273-286.

19. Instituto de Pesquisa e Estudos Florestais. Lista de sementes de Eucaliptus e Pinus. 2012. Disponível em: <http://www.ipef.br/sementes/eucapinus. asp>. Acesso em: 10 de julho de 2012.

7. Azevedo, L. A. S. Resistência parcial de genótipos de soja a Phakopsorapachyrhizi e sua interação com fungicidas. 2005. 68 f. Tese (Doutorado em Agronomia - Produção Vegetal) - Universidade Estadual Paulista, Jaboticabal. 
21. Junghans, D. T.; Alfenas, A. C.; Maffia, L. A. Escala de notas para quantificação da ferrugem em Eucalyptus. Fitopatologia Brasileira, Brasília, v. 28, p. 184-188, 2003.

22. Malavolta, V. M. A.; Pettinelli, J. R. A.; Fantin, G. M.; Souza, T. M. W. Determinação de níveis de resistência parcial à brusone em cinco genótipos de arroz. Summa Phytopathologica, Botucatu, v. 21, n. 2, p. 117-123, 1995.

23. Martins, J. A. S.; Juliatti, F. C.; Santos, V. A.; Polizel, A. C.; Juliatti, F. C. Período latente e uso da análise de componentes principais para caracterizar a resistência parcial à ferrugem da soja. Summa Phytopathologica, Botucatu, v.33, n.4, p.364-371, 2007.

24. Mckinney, H. H. Influence of soil, temperature and moisture on infection of wheat seedlings by Helminthosporium sativum. Journal of Agricultural Research, Washington, v. 26, p. 195-217, 1923.

25. Ruiz, R. A. R.; Alfenas, A. C.; Ferreira, F. A.; Valle, F. X. R. Influência de temperatura, do tempo de molhamento foliar, fotoperíodo e da intensidade de luz sobre a infecção de Pucciniapsidiiem eucalipto. Fitopatologia Brasileira, Brasília, v. 14, p. 55-61, 1989a.

26. Ruiz, R. A. R.; Alfenas, A. C.; Maffia, L. A.; Barbosa, M. M. Progresso da ferrugem do eucalipto, causada por Pucciniapsidii, em condições de campo. Fitopatologia Brasileira, Brasília, v. 14, p. 73-81, 1989 b.

27. Santos, M. R. Resistência genética à ferrugem em Eucalyptuspellitae E. urophyllax E. grandis.2011. 47p. Dissertação (Mestrado em Genética e Melhoramento) - Universidade Federal de Viçosa, Viçosa.

28. Shaner, G.; Hess, F. D. Equations for integrating components of slow leafrusting in wheat. Phytopathology, St. Paul, v. 68, p. 1464-1469, 1978.

29. Zauza, E. A. V.; Alfenas, A. C.; Old, K.; Couto, M. M. F.; Graça, R. N.; Maffia, L. A. Myrtaceae species resistance to rust caused by Pucciniapsidii. Australian Plant Pathology, Australia, n. 39, p. 406$411,2010$. 